\title{
Chemosensitivity Assay
}

National Cancer Institute

\section{Source}

National Cancer Institute. Chemosensitivity Assay. NCI Thesaurus. Code C18215.

A laboratory test to see how well a particular chemotherapy drug kills cancer cells. The test is done after the tumor cells are removed from the body. The assay may help in choosing the best drug or drugs for the cancer being treated. 